
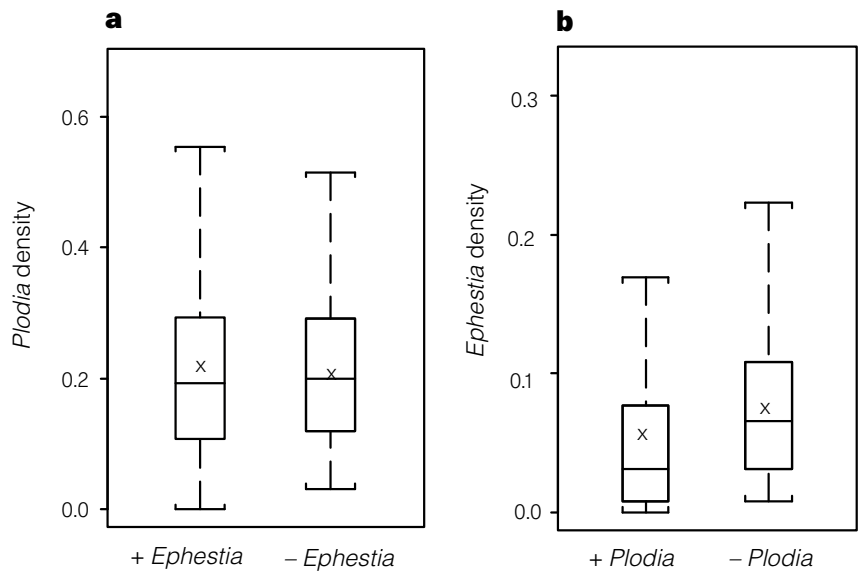

Figure 3 Box plots for $\mathbf{a}$, E. kuehniella, and $\mathbf{b}$, P. interpunctella in the presence (+) or absence ( - ) of the other host species. The solid line within each box marks the median; the cross marks the mean value. The length of the box is the interquartile range and the limit bars show the distance to 1.5 times the interquartile range giving a measure of dispersion in the data. The plots show the density of each species over a nine-week period. A repeated-measures analysis of variance (following a square-root transformation) reveals that the interaction mediated via the shared parasitoid, $V$. canescens, is amensal. The effects of apparent competition are extremely skewed, with one host suffering very little while the other is driven to extinction.

assemblages may be particularly prone to these indirect effects (compare with other natural enemy-victim systems) because parasitoids tend to have a pronounced numerical response and to limit host population sizes well below their carrying capacities $^{18}$. Generalist predators, on the other hand, will often show weaker numerical responses to particular prey species and therefore be less likely to cause species exclusion through apparent competition $^{19}$.

Received 17 March; accepted 28 April 1997.

1. Law, R. \& Watkinson, A. R. in Ecological Concepts (ed. Cherrett, J. M.) (Blackwell Scientific, London, 1989)

2. Lawton, J. H. \& Hassell, M. P. Asymmetrical competition in insects. Nature 289, 793-795 (1981).

3. Menge, B. A. Indirect effects in marine rocky intertidal interaction webs-patterns and processes. Ecol. Monogr. 65, 21-74 (1995).

4. Strauss, S. Y. Indirect effects in community ecology: their definition, study and importance. Trends Ecol. Evol. 6, 206-210 (1991).

5. Wootton, J. T. The nature and consequences of indirect effects in ecological communities. Annu. Rev Ecol. Sys. 25, 443-466 (1994).

6. Holt, R. D. \& Lawton, J. H. Apparent competition and enemy-free space in insect host-parasitoid communities. Am. Nat. 142, 623-645 (1993).

7. Holt, R. D. Predation, apparent competition and the structure of prey communities. Theor. Pop. Biol. 12, 197-229 (1977)

8. Holt, R. D. Spatial heterogeneity, indirect interactions and the coexistence of prey species. Am. Nat. 124, 377-406 (1984)

9. Williamson, M. H. An elementary theory of interspecific competition. Nature 180, 422-425 (1957).

10. Müller, C. B. \& Godfray, H. C. J. Apparent competition between two aphid species. J. Anim. Ecol. 66, $57-64$ (1997)

11. Karban, R., Houghen-Eitzmann, D. \& English-Loeb, G. Predator-mediated apparent competition between two herbivores that feed on grapevines. Oecologia 97, 508-511 (1994).

12. Settle, W. H. \& Wilson, L. T. Invasion by the variegated leafhopper and biotic interactions: parasitism, competition and apparent competition. Ecology 71, 1461-1470 (1990).

13. Schmitt, R. J. Indirect interactions between prey: apparent competition, predator aggregation and habitat segregation. Ecology 68, 1887-1897 (1987).

14. Hanley, K. A., Vollmer, D. M. \& Case, T. J. The distribution and prevalence of helminths, coccidia an blood parasites in two competing species of gecko: implications for apparent competition. Oecologia 102, 220-229 (1994)

15. Grosholz, E. D. Interactions of intraspecific, interspecific and apparent competition with hostpathogen dynamics. Ecology 73, 507-514 (1992).

16. Bonsall, M. B. Temporal and Spatial Insect Population Dynamics Thesis, Univ. London (1997).

17. Evans, E. W. \& England, S. Indirect interactions in biological control of insects: pests and natural enemies in alfalfa. Ecol. Appl. 6, 920-930 (1996).

18. Beddington, J. R., Free, C. A. \& Lawton, J. H. Characteristics of successful natural enemies in models of biological control of insect pests. Nature 273, 513-519 (1978).

19. Holt, R. D. in Multitrophic Interactions in Terrestrial Systems (eds Gange, A. C. \& Brown, V. K.) (Blackwell Scientific, London, 1996)

Acknowledgements. We thank R. Holt for comments on an earlier version of the manuscript. This work was supported by an NERC studentship to M.B.B. and an NERC-funded research grant to M.P.H.

Correspondence and requests for materials to be addressed to M.B.B. (e-mail: m.bonsall@ic.ac.uk).

\section{Genetic interaction between male mating strategy and sex ratio in a marine isopod}

\author{
Stephen M. Shuster ${ }^{\star}$ Clay Sassaman $\dagger$
}

${ }^{*}$ Department of Biological Sciences, Northern Arizona University, Flagstaff, Arizona 86011-5640, USA

$\dagger$ Department of Biology, University of California, Riverside, California 92521, USA

Individual males in many animal species exhibit discrete modes of behaviour $^{1-3}$, but the genetic mechanisms underlying these differences are poorly understood. Here we investigate the genetics of the isopod crustacean Paracerceis sculpta, in which three different types of males coexist, each distinguishable from the others by their behavioural and morphological phenotypes ${ }^{4,5}$. Within families, alleles of the gene encoding the enzyme phosphoglucomutase (Pgm gene) are associated with particular male phenotypes, although no significant association between these characters exists population-wide. This suggests that Pgm is closely linked to a single genetic locus which controls male phenotype. We call this the alternative mating strategy (Ams) locus. We present evidence that two other factors - an autosomal gene, transformer ( $T f r$ ), and an extrachromosomal factor-interact with primary sex determination loci and with alleles at Ams, causing certain individuals to change sex, thereby biasing family sex ratios. A model based on our genetic analysis suggests that: first, polymorphism in male behaviour is controlled by the mendelian segregation of three alleles at the Ams locus; second, that family sex ratio is influenced by alternative alleles at the $T f r$ locus whose expression is influenced by the extrachromosomal factor; and third, that $T f r$ and $A m s$ interact epistatically to determine the sex of the individual and, if male, its behaviour and external morphology.

Females are monomorphic in P. sculpta. Males, however, exhibit three distinct morphs that differ in reproductive behaviour: $\alpha$ males are largest and defend harems within sponges using elongated posterior appendages; $\beta$-males invade harems by mimicking female behaviour and morphology; and $\gamma$-males invade harems by being small and secretive ${ }^{5,6}$. A genetic model has been proposed ${ }^{7}$ to explain the persistence of the three male morphs at stable frequencies, in which three alleles at a single autosomal locus (Ams) show directional dominance and mendelian inheritance.

We tested this model $^{7}$ for male morphology using controlled laboratory crosses. We first examined mendelian inheritance at the Pgm locus ${ }^{8}$ in $25 / 31 \mathrm{~F}_{1}$ families in which one heterozygous and one homozygous parent were crossed. As three alleles were detectable at $P g m$, we summarized alleles possessed by heterozygous parents as allele 1 or allele 2 . The total numbers of progeny possessing these allele classes were 405 and 424, respectively, and individual crosses were homogeneous ( $G$-test (ref. 9), $G_{\mathrm{H}}=31.01$ ) (d.f. $=24$, $P>0.10)$. We considered Pgm inheritance to be mendelian.

The genetic model $^{7}$ suggested that field-collected $\beta$ - and $\gamma$-males are heterozygous at the Ams locus, and thus should produce 50:50 ratios of $\alpha$ - and $\beta$-, or $\alpha$ - and $\gamma$-male sons, respectively, when crossed with field-collected females (see Methods). As most $\beta$ - and $\gamma$-males were also heterozygous at the Pgm locus (11/13 and 7/10, respectively), we examined the association between Pgm genotype and male phenotype among $\mathrm{F}_{1}$ progeny. If these loci were unlinked, we expected the progeny of males heterozygous at both loci to segregate four combinations of the two male morphs and two Pgm genotypes in equal frequency. The more severe the deviation from this expectation, the closer the linkage, thus, parental and recombinant classes were each pooled, then compared using a $G$-test $(\text { d.f. }=1)^{9}$. 
Of the 351 male progeny reared from 18 double-heterozygote $P g m-A m s$ crosses, $96.3 \%$ appeared in the parental class $(G=368.9$, $P<0.001$ ), a result indicating that Ams is closely linked to Pgm (separated by four map units), and one consistent with the hypothesis that a major gene causes phenotypic differences among males ${ }^{7}$. We confirmed, moreover, that male differences are not simply due to allelic differences at Pgm. Electrophoretic analysis over a two-year period (1987-88) showed no evidence of linkage disequilibrium ${ }^{9}$ between $P g m$ allelomorphs and the three male morphs in nature $\left(D^{2}=0.004, P>0.10, N=292\right)$. Thus $P g m$ and Ams, although linked, represent distinct genetic loci.

To examine mendelian inheritance at Ams, we unambiguously

\section{Table 1 Paracerceis sculpta $F_{1}$ crosses}

\begin{tabular}{|c|c|c|c|c|c|c|c|c|c|c|c|c|}
\hline \multirow[b]{2}{*}{ Cross-class } & \multirow{2}{*}{$\begin{array}{l}\text { No. of } \\
\text { families }\end{array}$} & \multirow{2}{*}{$\begin{array}{l}\text { No. of } \\
\text { progeny }\end{array}$} & \multirow{2}{*}{$\begin{array}{l}\text { Weighted } \\
\text { survivorship }\end{array}$} & \multicolumn{5}{|c|}{ Progeny phenotypes } & $\begin{array}{c}\text { Expected } \\
\text { male frequency }\end{array}$ & \multirow[b]{2}{*}{$G_{A m s}$} & \multirow{2}{*}{$\begin{array}{l}\text { Proportion } \\
\text { of males } \dagger\end{array}$} & \multirow[b]{2}{*}{$G_{\text {sex ratio }}$} \\
\hline & & & & $\alpha$ & $\beta$ & $\gamma$ & $F$ & $N$ & $\alpha \quad \beta$ & & & \\
\hline $\begin{array}{l}A m s^{\alpha} A m s^{\alpha} \times A m s^{\alpha} A m s^{\alpha} \\
A m s^{\beta} m s^{\alpha} \times A m s^{\alpha} A m s^{\alpha} \\
A m s^{\beta} A m s^{\alpha} \times A m s^{\beta} A m s^{\alpha} \\
A m s^{\gamma} A m s^{\alpha} \times A m s^{\alpha} A m s^{\alpha}\end{array}$ & $\begin{array}{r}8 \\
12 \\
1 \\
10\end{array}$ & $\begin{array}{r}247 \\
1,308 \\
107 \\
921\end{array}$ & $\begin{array}{l}0.43 \\
0.49 \\
0.39 \\
0.38\end{array}$ & $\begin{array}{r}53 \\
59 \\
0 \\
75\end{array}$ & $\begin{array}{r}0 \\
267 \\
28 \\
0\end{array}$ & $\begin{array}{r}0 \\
0 \\
0 \\
105\end{array}$ & $\begin{array}{r}55 \\
317 \\
14 \\
167\end{array}$ & $\begin{array}{r}108 \\
643 \\
42 \\
347\end{array}$ & $\begin{array}{l}1.0: 0.00: 0.00 \\
0.50: 0.50: 0.00 \\
0.25: 0.75: 0.00 \\
0.50: 0.00: 0.50\end{array}$ & $\begin{array}{c}0.00 \\
143.60^{* *} \\
<0.001 \neq \\
5.02^{*}\end{array}$ & $\begin{array}{l}0.49 \\
0.51 \\
0.67 \\
0.52\end{array}$ & $\begin{array}{l}0.37 \\
0.13 \\
4.75^{\star} \\
0.49\end{array}$ \\
\hline & $\overline{31}$ & $\overline{2,583}$ & $\overline{0.44}$ & $\overline{187}$ & $\overline{295}$ & $\overline{105}$ & $\overline{553}$ & $\overline{1,140}$ & & & & \\
\hline
\end{tabular}

$F$, number of females; $N$, total progeny; $G_{A m s}=G_{\text {adj }}($ d.f. $=1)$ comparison of observed and expected male frequencies; $G_{\text {sex ratio }}=G_{\text {adj }}($ d.f. $=1)$ comparison of observed and $1: 1$ sex ratio. $* P<0.05 ; * * P<0.001$.

$\uparrow$ Proportion of males weighted by family size.

\$. Exact $\chi^{2}$ test.

\begin{tabular}{|c|c|c|c|c|c|c|c|c|c|}
\hline Cross-class & $P_{1} Q_{1}$ & $P_{1} Q_{2}$ & $P_{2} Q_{1}$ & $P_{2} Q_{2}$ & $N$ & $G_{p}$ & $G_{Q}$ & $G_{P, Q}$ & Inference \\
\hline \multirow[t]{10}{*}{$A m s^{\alpha} A m s^{\alpha} \times A m s^{\alpha} A m s^{\alpha}$} & 27 & 4 & 0 & 12 & 43 & $8.69^{*}$ & 2.85 & $33.00^{*}$ & Sex change $(1 \times)$ \\
\hline & 33 & 12 & 0 & 29 & 74 & 3.49 & 0.87 & $36.99 *$ & Sex change $(2 x)$ \\
\hline & 10 & 1 & 2 & 13 & 26 & 0.62 & 0.15 & $17.45^{*}$ & Sex change $(2 x)$ \\
\hline & 18 & 7 & 0 & 17 & 42 & 1.53 & 0.86 & $20.38^{*}$ & Sex change $(2 x)$ \\
\hline & 19 & 11 & 0 & 3 & 33 & $25.64^{*}$ & 0.76 & 3.18 & Sex change $(1 x) \dagger$ \\
\hline & 14 & 0 & 10 & 11 & 35 & 1.41 & $4.95^{*}$ & $6.44^{*}$ & Sex change $(1 \times) \dagger$ \\
\hline & 10 & 1 & 9 & 18 & 38 & $6.95^{*}$ & 0.00 & $8.88^{*}$ & Sex change $(1 \times)$ \\
\hline & 16 & 0 & 14 & 26 & 56 & $10.63^{*}$ & 0.29 & $14.65^{*}$ & Sex change $(1 \times)$ \\
\hline & 27 & 1 & 0 & 19 & 47 & 1.73 & 1.05 & $55.48^{*}$ & Sex change $(2 x)$ \\
\hline & 17 & 1 & 0 & 10 & 28 & 2.32 & 1.30 & $30.19 *$ & Sex change $(2 x)$ \\
\hline \multirow[t]{7}{*}{$A m s^{\gamma} A m s^{\alpha} \times A m s^{\alpha} A m s^{\alpha}$} & 4 & 7 & 0 & 0 & 11 & ** & 0.83 & 0.83 & Sex change $(1 x) \dagger$ \\
\hline & 5 & 5 & 6 & 9 & 25 & 1.01 & 0.36 & 0.36 & Independent assort \\
\hline & 4 & 6 & 13 & 15 & 38 & $8.88^{*}$ & 0.42 & 0.00 & Sex change $(1 \times) \dagger$ \\
\hline & 1 & 5 & 7 & 6 & 19 & 2.64 & 0.48 & 1.33 & Independent assort \\
\hline & 10 & 10 & 8 & 9 & 37 & 0.24 & 0.03 & 0.03 & Independent assort \\
\hline & 14 & 9 & 1 & 5 & 29 & $4.33^{*}$ & 0.47 & $5.94^{*}$ & Sex change $(1 x)$ \\
\hline & 3 & 7 & 12 & 7 & 29 & 2.84 & 0.03 & 2.84 & Independent assort \\
\hline
\end{tabular}

$P_{i}$, sex; $Q_{i}, P g m$ genotype: thus, $P_{1} Q_{1}$ represents $\beta$-males with $P g m$ allele class $1 ; P_{1} Q_{2}$ are $\alpha$-males with $P g m$ allele class $2 ; P_{2} Q_{1}$ are females bearing a $\beta$-allele as indicated by $P g m$ allele class 1 ; $P_{2} Q_{2}$ are females bearing an $\alpha$-allele as indicated by $P g m$ allele class 2. Inferences are explained in Methods. ${ }^{*} P<0.05 ; * * P<0.001$.

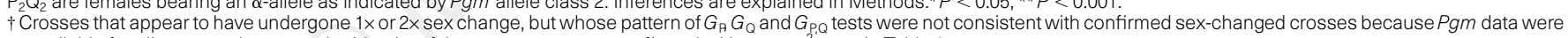
unavailable for all progeny; however, the identity of these crosses were confirmed with exact $\chi^{2}$ tests in Table $3 a$.

Table 3 Inheritance of $A m s$, Tfr and ECF in progeny of $P$. sculpta

\begin{tabular}{|c|c|c|c|c|c|c|c|c|c|c|c|c|c|c|c|}
\hline \multirow{4}{*}{$\begin{array}{l}\text { Ams cross-type } \\
\text { (a) Among } \mathrm{F}_{1} \text { progeny } \\
A m s^{\alpha} A m s^{\alpha} \times A m s^{\alpha} A m s^{\alpha} \\
A m s^{\beta} A m s^{\alpha} \times A m s^{\alpha} A m s^{\alpha}\end{array}$} & \multirow{2}{*}{ Tfr cross-type } & \multirow{2}{*}{ ECF state } & \multirow{2}{*}{$\begin{array}{l}\text { No. of } \\
\text { families }\end{array}$} & \multirow{2}{*}{$\begin{array}{l}\text { No. of } \\
\text { progeny }\end{array}$} & \multirow{2}{*}{$\begin{array}{l}\text { Weighted } \\
\text { survivorship }\end{array}$} & \multicolumn{4}{|c|}{ Observed } & \multicolumn{4}{|c|}{ Expected } & \multirow[b]{2}{*}{$N$} & \multirow{2}{*}{$\begin{array}{c}\text { Exact } \chi^{2} \\
\text { probability }\end{array}$} \\
\hline & & & & & & $\alpha^{-}$ & $\beta-$ & $\gamma^{-}$ & $F$ & $\alpha^{-}$ & $\beta-$ & $\gamma^{-}$ & $F$ & & \\
\hline & $T f r^{1} T f r^{1} \times T f r^{1} T f r^{1}$ & $M(-) ; F(-)$ & 1 & 85 & 0.34 & 15 & 0 & 0 & 14 & 14.5 & 0 & 0 & 14.5 & 29 & 1.00 \\
\hline & $T f r^{1} T f r^{2} \times T f r^{2} T f r^{2}$ & $\mathrm{M}(+) ; \mathrm{F}(-)$ & 2 & 194 & 0.72 & 0 & 37 & 0 & 87 & 0 & 45.88 & 0 & 78.12 & 124 & 0.11 \\
\hline & $T f r^{1} T f r^{2} \times T f r^{1} T f r^{2}$ & $\mathrm{M}(+) ; \mathrm{F}(-)$ & 1 & 95 & 0.49 & 5 & 13 & 0 & 29 & 2.82 & 20.68 & 0 & 23.5 & 47 & 0.06 \\
\hline & & & 1 & 115 & 0.41 & 3 & 9 & 0 & 35 & 2.82 & 20.68 & 0 & 23.5 & 47 & $0.00^{*}$ \\
\hline & $T f r^{1} T f r^{1} \times T f r^{2} T f r^{2}$ & $M(+) ; F(-)$ & 2 & 227 & 0.40 & 0 & 51 & 0 & 41 & 0 & 46 & 0 & 46 & 92 & 0.35 \\
\hline & $T f r^{1} T f r^{1} \times T f r^{1} T f r^{2}$ & $M(+) ; F(-)$ & 5 & 589 & 0.49 & 41 & 134 & 0 & 118 & 38.09 & 146.5 & 0 & 108.41 & 293 & 0.34 \\
\hline & $T f r^{1} T f r^{1} \times T f r^{1} T f r^{1}$ & $\mathrm{M}(+) ; \mathrm{F}(-)$ & 1 & 85 & 0.47 & 10 & 23 & 0 & 7 & 10 & 20 & 0 & 10 & 40 & 0.55 \\
\hline$A m s^{\beta} A m s^{\alpha} \times A m s^{\alpha} A m s^{\alpha}$ & $T f r^{1} T f r^{1} \times T f r^{2} T f r^{2}$ & $\mathrm{M}(+) ; \mathrm{F}(-)$ & 1 & 107 & 0.39 & 0 & 28 & 0 & 14 & 0 & 31.5 & 0 & 10.5 & 42 & 0.28 \\
\hline \multirow[t]{4}{*}{$A m s^{\gamma} A m s^{\alpha} \times A m s^{\alpha} A m s^{\alpha}$} & $T f r^{1} T f r^{2} \times T f r^{2} T f r^{2}$ & $M(-) ; F(-)$ & 1 & 93 & 0.16 & 1 & 0 & 4 & 10 & 1.8 & 0 & 3.75 & 9.45 & 15 & 0.87 \\
\hline & $T f r^{1} T f r^{1} \times T f r^{2} T f r^{2}$ & $\mathrm{M}(-) ; \mathrm{F}(-)$ & 6 & 579 & 0.39 & 47 & 0 & 47 & 132 & 56.5 & 0 & 56.5 & 113 & 226 & 0.05 \\
\hline & & & 1 & 94 & 0.36 & 5 & 0 & 11 & 18 & 8.5 & 0 & 8.5 & 17 & 34 & $0.02^{*}$ \\
\hline & $T f r^{1} T f r^{1} \times T f r^{1} T f r^{1}$ & $\mathrm{M}(-) ; \mathrm{F}(-)$ & 2 & 155 & 0.46 & 22 & 0 & 43 & 7 & 18 & 0 & 36 & 18 & 72 & 0.55 \\
\hline Totals & & & 24 & 2,418 & 0.43 & 149 & 295 & 105 & 512 & 153.03 & 331.24 & 104.75 & 471.98 & 1,061 & \\
\hline \multirow{3}{*}{$\begin{array}{l}\text { (b) Among } F_{2} \text { progeny } \\
A m s^{\alpha} A m s^{\alpha} \times A m s^{\alpha} A m s^{\alpha}\end{array}$} & & & & & & & & & & & & & & & \\
\hline & $T f r^{1} T f r^{2} \times T f r^{2} T f r^{2}$ & $\mathrm{M}(-) ; \mathrm{F}(+)$ & 2 & 52 & 0.58 & 0 & 0 & 0 & 30 & 0 & 0 & 0 & 30 & 30 & 1.00 \\
\hline & & $\mathrm{M}(-) ; \mathrm{F}(+)$ & 1 & 29 & 0.31 & 3 & 0 & 0 & 6 & 1.17 & 0 & 0 & 7.83 & 20 & 0.10 \\
\hline \multirow[t]{2}{*}{$A m s^{\alpha} A m s^{\alpha} \times A m s^{\beta} A m s^{\alpha}$} & $T f r^{1} T f r^{2} \times T f r^{2} T f r^{2}$ & $M(-) ; F(+)$ & 1 & 60 & 0.45 & 0 & 14 & 0 & 13 & 0 & 9.99 & 0 & 17.01 & 27 & 0.17 \\
\hline & $T f r^{1} T f r^{1} \times T f r^{2} T f r^{2}$ & $\mathrm{M}(-) ; \mathrm{F}(+)$ & 2 & 78 & 0.26 & 0 & 11 & 0 & 9 & 0 & 10 & 0 & 10 & 20 & 0.82 \\
\hline \multirow[t]{4}{*}{$A m s^{\beta} A m s^{\alpha} \times A m s^{\alpha} A m s^{\alpha}$} & $T f r^{1} T f r^{2} \times T f r^{2} T f r^{2}$ & $\mathrm{M}(+) ; \mathrm{F}(+)$ & 4 & 148 & 0.28 & 0 & 16 & 0 & 25 & 0 & 15.17 & 0 & 25.83 & 41 & 0.87 \\
\hline & $T f r^{1} T f r^{2} \times T f r^{1} T f r^{2}$ & $\mathrm{M}(+) ; \mathrm{F}(+)$ & 3 & 109 & 0.40 & 4 & 16 & 0 & 24 & 2.64 & 19.36 & 0 & 22 & 44 & 0.46 \\
\hline & $T f r^{1} T f r^{1} \times T f r^{2} T f r^{2}$ & $\mathrm{M}(+) ; \mathrm{F}(+)$ & 1 & 37 & 0.62 & 0 & 12 & 0 & 11 & 0 & 11.5 & 0 & 11.5 & 23 & 1.00 \\
\hline & $T f r^{1} T f r^{1} \times T f r^{1} T f r^{2}$ & $\mathrm{M}(+) ; \mathrm{F}(+)$ & 4 & 158 & 0.34 & 8 & 23 & 0 & 23 & 7.02 & 27 & 0 & 19.98 & 54 & 0.57 \\
\hline$A m s^{\beta} A m s^{\alpha} \times A m s^{\beta} A m s^{\alpha}$ & $T f r^{1} T f r^{2} \times T f r^{2} T f r^{2}$ & $M(+) ; F(+)$ & 1 & 46 & 0.57 & 0 & 15 & 0 & 11 & 0 & 14.62 & 0 & 11.38 & 26 & 1.00 \\
\hline$A m s^{\beta} A m s^{\alpha} \times A m s^{\gamma} A m s^{\alpha}$ & $T f r^{1} T f r^{2} \times T f r^{2} T f r^{2}$ & $\mathrm{M}(+) ; \mathrm{F}(-)$ & 2 & 63 & 0.35 & 0 & 8 & 8 & 6 & 0 & 8.14 & 4.18 & 9.68 & 22 & 0.08 \\
\hline \multirow[t]{2}{*}{$A m s^{\gamma} A m s^{\alpha} \times A m s^{\alpha} A m s^{\alpha}$} & $T f r^{1} T f r^{2} \times T f r^{2} T f r^{2}$ & $\mathrm{M}(-) ; \mathrm{F}(+)$ & 1 & 36 & 0.39 & 0 & 0 & 6 & 8 & 1.82 & 0 & 3.5 & 8.68 & 14 & 0.15 \\
\hline & $T f r^{1} T f r^{2} \times T f r^{2} T f r^{2}$ & $\mathrm{M}(-) ; \mathrm{F}(+)$ & 1 & 44 & 0.43 & 1 & 0 & 7 & 11 & 4.75 & 0 & 4.75 & 9.5 & 19 & 0.13 \\
\hline \multirow[t]{2}{*}{$A m s^{\gamma} A m s^{\alpha} \times A m s^{\beta} A m s^{\alpha}$} & $T f r^{1} T f r^{2} \times T f r^{2} T f r^{2}$ & $\mathrm{M}(-) ; \mathrm{F}(+)$ & 1 & 40 & 0.65 & 0 & 15 & 0 & 11 & 0 & 9.62 & 3.38 & 13 & 26 & $0.04^{*}$ \\
\hline & $T f r^{1} T f r^{1} \times T f r^{1} T f r^{2}$ & $\mathrm{M}(-) ; \mathrm{F}(+)$ & 1 & 35 & 0.40 & 0 & 6 & 0 & 8 & 0 & 7 & 1.82 & 5.18 & 14 & 0.23 \\
\hline \multicolumn{2}{|l|}{ Totals } & & 25 & 935 & 0.40 & 16 & 136 & 21 & 196 & 25.98 & 132.4 & 17.63 & 192.99 & 369 & \\
\hline
\end{tabular}

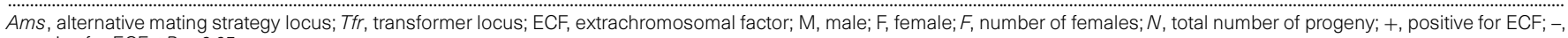
negative for ECF. ${ }^{*} P<0.05$. 
assigned parental males and females to four cross-classes using Pgm genotypes in phase with $\alpha$-, $\beta$ - and $\gamma$-male phenotypes (Table 1 ). We pooled the total progeny within cross-classes to obtain the observed frequencies of females and males of different phenotypes. We then compared these frequencies with those predicted by the genetic model ${ }^{7}$. The predicted phenotypes appeared in the four cross-classes (Table 1), a result consistent with the presumed dominance relationships among the $A m s$ alleles $\left(A m s^{\beta}>A m s^{\gamma}>A m s^{\alpha}\right)^{7}$. However, according to strict mendelian expectations, crosses involving $\beta$ - and $\gamma$-sires showed an excess of $\beta$ - and $\gamma$-sons, respectively (Table 1 ). Moreover, pooled sex ratios deviated from unity only in cross-class 3 (Table 1), whereas family sex ratios within cross-classes 2 and 4 were heterogeneous $\left(G_{\mathrm{H}}=62.88\right.$ (d.f. $=9$, $P<0.001$ ) and 19.45 (d.f. $=5, P<0.005)$, respectively). Given evidence that $P g m$ and Ams are closely linked, apparent mendelian inheritance at Pgm, but not at Ams, as well as heterogeneous sex ratios within cross-classes, indicated that additional factors must influence male phenotype.

Both genetic and extrachromosomal factors affect family sex ratios in peracarid crustaceans ${ }^{10-17}$. Certain autosomal genes cause genetic females to mature as males, whereas extrachromosomal factors (from either bacteria or virions) appear to produce the opposite effect $\mathrm{t}^{10-17}$. As the Pgm/Ams complex in P. sculpta is autosomal ${ }^{7}$, we reasoned that if sex-ratio biasing factors exist, they should cause deviations in the observed frequencies of Pgm alleles between males and females, in the same families that showed sex-ratio biases and excesses of $\beta$ - and $\gamma$-males. Differently put, if sex-ratio biasing factors caused males to mature as females and females to mature as males, we predicted an apparent interaction between Pgm and sex, even though these traits were unlinked (Fig. 1).

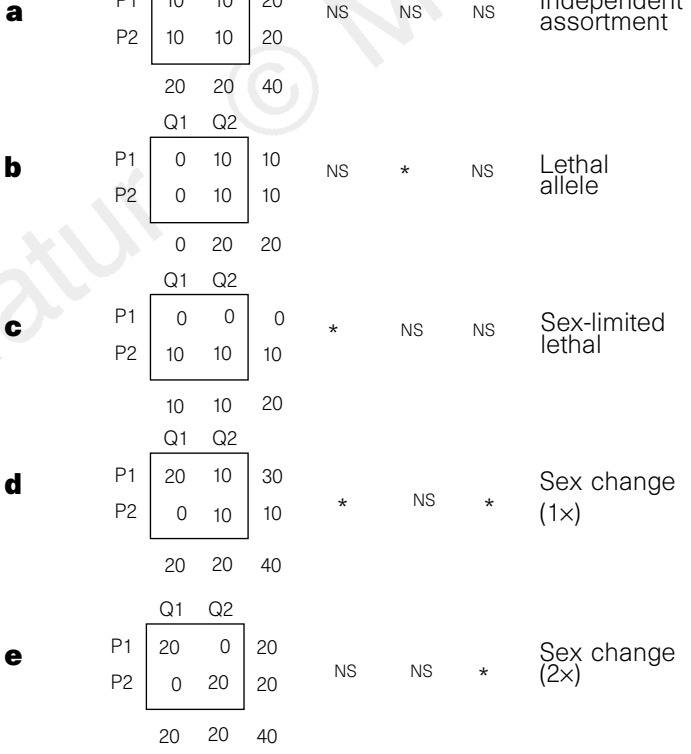

Figure 1 Detection of sex-ratio biasing factors in P. sculpta. $2 \times 2$ tables show hypothetical allelic combinations among 40 progeny produced by a $P_{1} P_{1}, Q_{1} Q_{2}$ male crossed with a $P_{1} P_{2}, Q_{1} Q_{1}$ female; $P$ represents sex $\left(P_{1}\right.$, males; $P_{2}$, females); $Q=\operatorname{Pgm}\left(Q_{1}\right.$, allele class $1 ; Q_{2}$, allele class 2$) ; G$ tests $\left(G_{P}, G_{Q}, G_{P, Q}\right)$ show significant (asterisk) and non-significant (NS) deviations in sex ratio and Pgm allele frequency, as well as interactions between sex and Pgm; a, independent assortment; $\mathbf{b}$, lethal allele indicates mortality regardless of sex; $\mathbf{c}$, sex-limited lethal indicates mortality regardless of $Q_{i}$ genotype; $\mathbf{d}, P_{2} Q_{1}$ interaction causes females to mature as males; e, $P_{2} Q_{1}$ and $P_{1} Q_{2}$ interactions cause females to mature as males and males to mature as females.
To test this hypothesis, we examined the distribution of $\mathrm{Pgm}$ alleles among male and female progeny in $\mathrm{F}_{1}$ cross-classes 2 $\left(A m s^{\beta} A m s^{\alpha} \times A m s^{\alpha} A m s^{\alpha}\right)$ and $4\left(A m s^{\gamma} A m s^{\alpha} \times A m s^{\alpha} A m s^{\alpha}\right)$ (Tables 1, 2). Independent assortment occurred in $4 / 17 \mathrm{~F}_{1}$ crosses, all involving $\gamma$-sires. The remaining $13 / 17 \quad F_{1}$ crosses showed evidence of one-way or two-way sex change (Table 2), indicating that sex-ratio biasing factors exist in P. sculpta. Lethal sexlimited or autosomal alleles are unlikely to have produced these deviations because sex-ratio biases occurred in both directions ( $G_{\mathrm{P}}$ in Table 2), and because Pgm showed mendelian inheritance in $16 / 17$ crosses $\left(G_{\mathrm{Q}}\right.$ in Table 2$)$. Variation in male-morph and sex-ratio frequencies, within cross-classes presumed to be homogeneous with respect to their Ams- and sex-determination genotypes (for example, cross-classes 2 and 4, in Table 2), indicated that expression of sex-ratio biasing factors is contingent on individuals' allelic states at $\mathrm{Pgm} / \mathrm{Ams}$ and at primary sex-determination loci. Moreover, evidence of two-way sex change suggested that sex-ratio biasing factors in P. sculpta were both genetic and extrachromosomal ${ }^{10,12,13,15-17}$.

We devised a model to explain the observed variation in $F_{1}$ phenotype frequencies in which one autosomal ( $T f r$, for transformer) and one extrachromosomal factor (ECF) exist (factor effects are explained in Methods; Fig. 2). Like previous hypotheses regarding sex-ratio biasing factors ${ }^{10,12,13,15-17}$, we assumed that primary sex determination involved female heterogamety ${ }^{7}$. Unlike previous models, however, we assumed that two-way sex change is caused by alternative alleles at a single autosomal locus ( $T f r)$, and that the effects of ECF are contingent on allelic states at Ams, Tfr and primary sex-determination loci (Fig. 2). Our model thus provided a testable explanation for male- and female-biased sex ratios, for oneand two-way sex change, for the inheritance of the Pgm/Ams

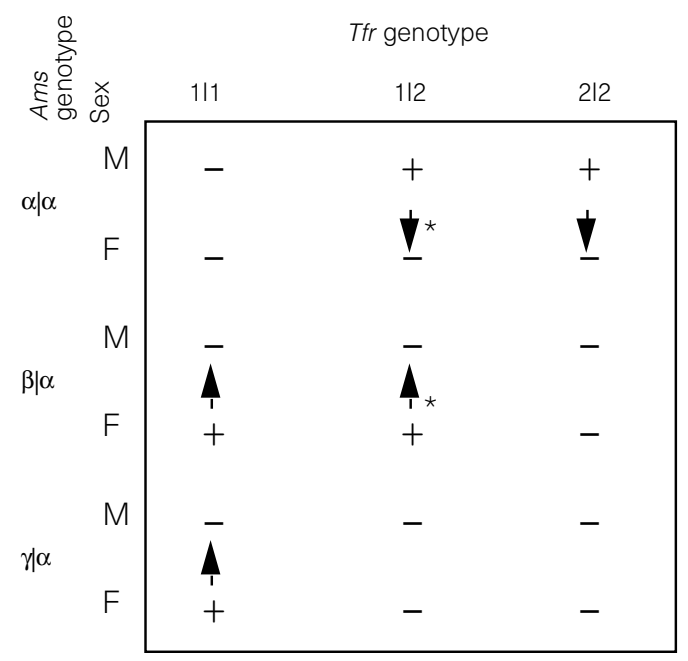

Figure 2 Effects of Tfr and ECF on Ams and primary sex determination loci: $\alpha, \beta, \gamma$ are alleles at Ams; M, male; F, female; Tfr' represent alleles at Tfr; minus sign, no effect of Tfr on Ams-sex combination; plus sign, sex change, with an arrow indicating the direction of change; asterisk, effect produced by interaction of ECF with Tfr, Ams and primary sex-determination genotypes. The apparent effect of ECF is to enhance or suppress the expression of the $T f^{2}$ allele depending on allelic states an individual's Ams and primary sex-determination loci. 
complex, and for the surplus of $\beta$ - and $\gamma$-males in $F_{1}$ families (Table 1; Fig. 3).

We tested our model by assigning Ams and Tfr genotypes, as well as ECF states (Table 3a) to all parental individuals using unambiguous Pgm genotypes and apparent Tfr genotypes (Table 2). We then compared observed and expected frequencies of male and female $\mathrm{F}_{1}$ progeny using exact $\chi^{2}$ tests $^{18}$. We found no significant deviation of observed from expected frequencies in 22/24 $\mathrm{F}_{1}$ families (for $N$ progeny, $N=1,061$; Table $3 \mathrm{a}$ ). Moreover, the presumed Tfrgenotypes of parental individuals conformed to Hardy-Weinberg expectations (exact $\chi^{2}=0.21$ ).

We further tested our model by combining (1) unambiguous Ams genotypes (determined from the $P g m$ genotypes of $\mathrm{F}_{1}$ parents and $\mathrm{F}_{2}$ families; Tables 1,2), with (2) predicted Tfr genotypes for $F_{2}$ progeny (determined from the apparent Tfr genotypes of their $\mathrm{F}_{1}$ parents; Table 2), with (3) the predicted ECF state of $F_{2}$ progeny (determined from the apparent ECF state of their $\mathrm{F}_{1}$ parents; Table $3 a)$, to generate expected male-morph frequencies and sex ratios for all $\mathrm{F}_{2}$ progeny (Table $3 \mathrm{~b}$ ). Using the same methods for comparing observed and expected progeny frequencies as those described for $F_{1}$ families, we found no significant deviation in male morph or sex ratios in 24/25 $\mathrm{F}_{2}$ families (Table $3 \mathrm{~b}$ ). Although ECF was initially detectable only in parental $\beta$-males, this factor was evidently transmitted to individuals of both sexes, because this factor's interaction with a range of $A m s$ and $T f r$ genotypes predictably biased $F_{1}$ and $F_{2}$ family sex ratios (Table $3 b$ ).

The relative frequencies of the three male morphs, as well as local sex ratios, are known to influence male and female fitness in $P$. sculpta ${ }^{7,19,20}$. Biases in male morph and sex ratios, moreover, arise and vanish without pattern within patchily distributed spongocoels ${ }^{6,20}$. Conditional strategies are unlikely to evolve in such unpredictable environments ${ }^{21-24}$. Thus, our model of interaction between Ams, Tfr, ECF and primary sex-determination loci is consistent with known aspects of this species' biology and with

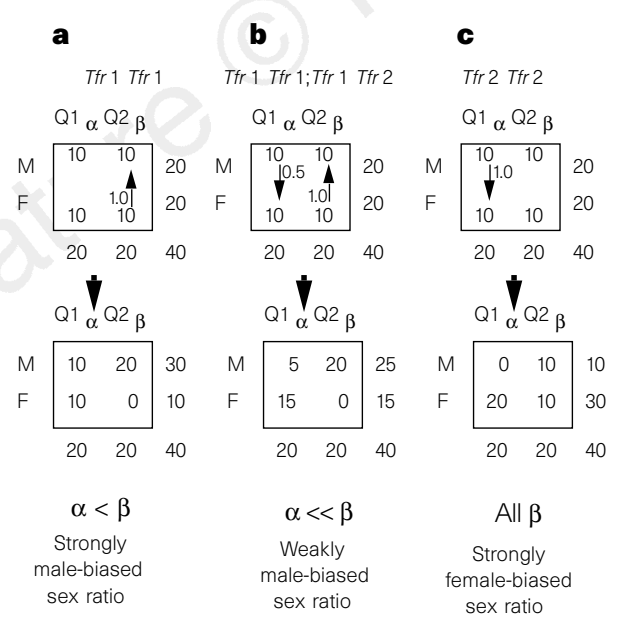

Figure 3 Effects of Tfr and ECF on mendelian inheritance at the Ams locus: upper $2 \times 2$ tables show hypothetical allelic combinations among 40 progeny from $\mathrm{Q}_{1 \alpha} \mathrm{Q}_{1 \alpha}$ female $\times \mathrm{Q}_{1 \alpha} \mathrm{Q}_{2 \beta}$ male crosses $\left(\mathrm{Q}_{i j}\right.$, Pgm/Ams complex, where $i$ is the Pgm allele and $j$, the Ams allele; $M$, males; $F$, females); small arrows indicate sex transformations resulting from epistatic and extrachromosomal interactions; Tfr genotypes are shown above each upper table; the numbers near the arrows indicate the proportions of transforming individuals; large arrows point to lower $2 \times 2$ tables, which show the results of sex transformations on $\alpha: \beta$ male morphand sex ratios; a, $\operatorname{Tfr}^{1} \operatorname{Tfr}^{1}, \mathrm{Q}_{1 \alpha} \mathrm{Q}_{2 \beta}$ females mature as males; $\mathbf{b}, \operatorname{Tfr}^{1} \operatorname{Tfr}^{2}, \mathrm{Q}_{1 \alpha} \mathrm{Q}_{1 \alpha}$ males mature as females owing to ECF; all $Q_{1 \alpha} Q_{2 \beta}$ females mature as $\beta$ males owing to $T f r$ and $A m s$ interaction; c, $\operatorname{Tfr}^{2} T^{2}{ }^{2}, Q_{1 \alpha} Q_{1 \alpha}$ males mature as females. established theory. Our results demonstrate the mendelian inheritance of male mating behaviour and sex factor loci, whose alleles interact with each other, as well as with an apparent extrachromosomal sex-ratio biasing factor. Interactions among these factors could rapidly shift population sex ratios in response to the dynamics of this species' mating system. Allele frequencies at Ams and Tfr conform to Hardy-Weinberg expectations ${ }^{7}$ (Table 3a), perhaps because fitness interactions between alleles at both loci cycle rapidly $^{3,25}$. Thus our results also demonstrate that genetic polymorphisms and epistasis affecting fitness can arise and persist in nature ${ }^{26,27}$

\section{Methods}

Genetic crosses and electrophoresis. Male isopods and virgin females ${ }^{28}$ were collected from sponges ${ }^{6,29}$ and maintained as pairs until females became gravid $^{6}$. The $F_{1}$ generation included eight $\alpha$-males, six $\beta$-males and five $\gamma$ males, each crossed to haphazardly selected females, to yield eight $\alpha$-families, $13 \beta$-families and $10 \gamma$-families. We reared $F_{1}$ animals to maturity ${ }^{7}$ and produced an $F_{2}$ generation from six $F_{1} \alpha$-males, $13 F_{1} \beta$-males and four $F_{1} \gamma$ males each crossed with $F_{1}$ daughters of $\beta$-males, as well as two $F_{1} \beta$-males each crossed to $F_{1}$ daughters of $\gamma$-males. $F_{2}$ animals were reared under the same conditions as $F_{1}$ animals. Tissue samples from all adults of each generation were electrophoresed and stained for Pgm activity ${ }^{8}$.

Estimation of expected Ams frequencies for the $\mathrm{F}_{1}$. Previously described methods ${ }^{7}$ estimate that over $99 \%$ of field-collected individuals possess $A m s^{\alpha} A m s^{\alpha}$ (0.86), $A m s^{\beta} A m s^{\alpha}$ (0.02) or $A m s^{\gamma} A m s^{\alpha}$ (0.11) genotypes ${ }^{7}$, limiting the possible allelic combinations for $\mathrm{F}_{1}$ progeny. Females are evidently heterogametic in this and in related sphaeromatid species (S.M.S. and C.S., unpublished electrophoretic data) ${ }^{10,17,30}$. Thus, we presumed that P. sculpta females carry alleles at the Ams locus at the same frequencies as described for males, and we expected primary sex ratios to equal unity.

Detection of genetic interactions. The genetic model ${ }^{7}$ indicated that the Pgm/Ams complex and primary sex determination loci in P. sculpta are unlinked. Thus, a cross between a homogametic male, heterozygous at $P g m / A m s$, and a heterogametic female, homozygous at Pgm/Ams, would yield four combinations of two sexes and two Pgm genotypes in equal frequency. Using $\mathrm{P}_{1}$ to represent males and $\mathrm{P}_{2}$ for females, $\mathrm{Q}_{1}$ as $P g m$ allele class 1 and $\mathrm{Q}_{2}$ as $P g m$ allele class 2 , we plotted the four progeny genotypes in a $2 \times 2$ table (Fig. 1a) and examined deviations in the table using $G$-tests. We identified sex-ratio biases by comparing $\Sigma\left(\mathrm{P}_{1} \mathrm{Q}_{i}\right)$ with $\Sigma\left(\mathrm{P}_{2} \mathrm{Q}_{i}\right)=G_{\mathrm{P}}$, deviations from mendelian expectations at $P g m$ by comparing $\Sigma\left(\mathrm{P}_{i} \mathrm{Q}_{1}\right)$ with $\Sigma\left(\mathrm{P}_{i} \mathrm{Q}_{2}\right)=G_{\mathrm{Q}}$, and interactions between sex ratio and Pgm frequency by comparing $\left(\mathrm{P}_{1} \mathrm{Q}_{1}+\mathrm{P}_{2} \mathrm{Q}_{2}\right)$ with $\left(\mathrm{P}_{1} \mathrm{Q}_{2}+\mathrm{P}_{2} \mathrm{Q}_{1}\right)=G_{\mathrm{P}, \mathrm{Q}}$. We predicted five possible patterns of $G_{\mathrm{P}} G_{\mathrm{Q}}$ and $G_{\mathrm{P}, \mathrm{Q}}$ deviations among the $\mathrm{F}_{1}$ families (shown in Fig. 1): a, independent assortment between primary sex factors and the $\mathrm{Pgm} /$ Ams complex would yield four combinations of two sexes and two Pgm genotypes in equal frequency, no significant $G_{\mathrm{P}} G_{\mathrm{Q}}$ and $G_{\mathrm{P}, \mathrm{Q}}$ deviations, and indicate no effect of sex-ratio biasing factors; $b$, lethal factors causing mortality unrelated to sex would cause deficiencies in the frequencies of $P g m$ alleles, significant $G_{\mathrm{Q}}$ deviations, but no deviations in sex ratio $\left(G_{\mathrm{P}}\right)$, and no interaction between Pgm and sex $\left(G_{\mathrm{P}, \mathrm{Q}}\right)$; c, factors causing sex-limited mortality would cause consistent deficiencies in the frequency of one or the other sex, consistent $G_{\mathrm{P}}$ deviations, but no deviations in $\operatorname{Pgm}$ frequency $\left(G_{\mathrm{Q}}\right)$, and no interaction between $P g m$ and sex $\left(G_{\mathrm{P}, \mathrm{Q}}\right)$; d, factors causing one-way sex change (genetic males maturing as females, for example) would cause no deviation in Pgm frequencies $\left(G_{\mathrm{Q}}\right)$, but would generate consistent sex-ratio $\left(G_{\mathrm{P}}\right)$ deviations, as well as significant $P g m$-sex interactions $\left(G_{\mathrm{P}, \mathrm{Q}}\right)$; e, factors causing two-way sex change would only show significant $G_{\mathrm{P}, \mathrm{Q}}$ interactions.

Effects of Tfr and ECF. We let Tfr be a diallelic, autosomal locus whose alleles $\left(T f r^{1}, T f r^{2}\right)$ interact with, but assort independently of, alleles at Ams and at primary sex-determination loci (Fig. 2). $T f r^{1} T f r^{1}$ was assumed to have no effect on males of any Ams genotype, and no effect on $A m s^{\alpha} A m s^{\alpha}$ females. However, females bearing $T f r^{1} T f r^{1}$, as well as $\beta$ - or $\gamma$-alleles at $A m s$, were assumed to mature as males, with phenotypes determined by their $A m s$ allelic state. $T f r^{2} T f r^{2}$ was assumed to have no effect on females of any Ams genotype, and no effect on $\beta$ - or $\gamma$-males. However, $A m s^{\alpha} A m s^{\alpha}$ males bearing $T f r^{2} T f r^{2}$ were assumed to mature as females. $T f r^{1} T f r^{2}$ heterozygotes were assumed to affect 
only individuals descended from field-collected $\beta$-males, and then affect only two Ams genotypes: $T f r^{1} T f r^{2}$ females bearing $\beta$-alleles were assumed to mature as $\beta$-males, and $T f r^{1} T f r^{2}, A m s^{\alpha} A m s^{\alpha}$ males were assumed to mature as females. This latter effect assumed that the $T f r^{2}$ allele interacts with ECF, which initially occurred only in parental $\beta$-males, but which was transmitted to $F_{1-2}$ individuals of both sexes and a range of Ams genotypes (Table $3 \mathrm{~b}$ ).

Testing the model. In Tables $3 \mathrm{a}, \mathrm{b}$, exact probabilities were Bonferroniadjusted $(0.05 / k$, where $k$ is the number of tests) when multiple crosses with identical Ams and Tfr genotypes, as well as ECF states were tested; similar crosses with nonsignificant exact probabilities were pooled and the exact $\chi^{2}$ probability for the pooled frequencies reported; primary sex-determination genotypes were unambiguously determined from $P g m$ genotype frequencies within families; the apparent $T f r$ genotypes among 36 parents ( 24 crosses) were $15 T f r^{1} T f r^{1}, 12 T f r^{1} T f r^{2}$ and $9 T f r^{2} T f r^{2}$; expected genotypes calculated from inferred allele frequencies conform to Hardy-Weinberg expectations, exact $\chi^{2}$ probability 0.21 .

Received 21 January; accepted 24 April 1997.

1. Lank, D. B., Smith, C. M., Hanotte, O., Burke, T. \& Cooke, F. Genetic polymorphism for alternative mating behaviour in lekking male ruff. Nature 378, 59-62 (1995).

2. Gross, M. R. Alternative reproductive strategies and tactics; diversity within sexes. Trends Ecol. Evol. 11, 92-97 (1996)

3. Sinervo, B. \& Lively, C. M. The rock-paper-scissors game and the evolution of alternative male strategies. Nature 380, 240-243 (1996)

4. Shuster, S. M. Alternative reproductive behaviors: Three discrete male morphs in Paracerceis sculpta, an intertidal isopod from the northern Gulf of California. I. Crust. Biol. 7, 318-327 (1987).

5. Shuster, S. M. The reproductive behaviour of $\alpha-, \beta-$, and $\gamma$-males in Paracerceis sculpta, a marine isopod crustacean. Behaviour 121, 231-258 (1992).

6. Shuster, S. M. Male alternative reproductive behaviors in a marine isopod crustacean (Paracerceis sculpta): The use of genetic markers to measure differences in fertilization success among $\alpha-, \beta$ - and $\gamma$ males. Evolution 34, 1683-1698 (1989).

7. Shuster, S. M. \& Wade, M. J. Equal mating success among male reproductive strategies in a marine isopod. Nature 350, 606-61 (1991).

8. Sassaman, C. Inbreeding and sex ratio variation in female-biased populations of a clam shrimp, Eulimnadia texana. Bull. Mar. Sci. 45, 425-432 (1989).

9. Hartl, R. \& Clark, A. in Principles of Population Genetics 2nd edn, 47-57 (Sinauer, Sunderland, MA, 1989)

10. Heath, D. J. \& Ratford, J. R. The inheritance of sex ratio in the isopod, Sphaeroma rugicauda. Heredity 64, 419-425 (1990).

11. Bull, J. J. Evolution of Sex Determining Mechanisms (Benjamin-Cummings, Menlo Park, CA, 1983).

12. Legrand, J. J., Legrand-Hamelin, E. \& Juchault, P. Sex determination in Crustacea. Biol. Rev. 62, 439 470 (1987).

13. Juchault, P., Rigaud, T. \& Mocquard, J.-P. Evolution of sex-determining mechanisms in a wild population of Armadillidium vulgare Latr. (Crustacea: Isopoda): competition between two feminizing parasitic sex factors. Heredity 69, 382-390 (1992).

14. Rousset, F., Bouchon, D., Pintureau, B., Juchault, P. \& Solignac, M. Wolbachia endosymbionts responsible for various alterations of sexuality in Arthropods. Proc. R. Soc. Lond. B 250, 91-98 (1991)

15. Hurst, L. D. The incidences, mechanisms and evolution of cytoplasmic sex ratio distorters in animals. Biol. Rev. 68, 121-193 (1993)

16. Rigaud, T. \& Juchault, P. Conflict between feminizing sex ratio distorters and an autosomal masculinizing gene in the terrestrial isopod, Armadillidium vulgare Latr. Genetics 133, 247-252 (1993).

17. Juchault, P. \& Rigaud, T. Evidence for female heterogamety in two terrestrial crustaceans and the problem of sex chromosome evolution in isopods. Heredity 75, 488-471 (1995).

18. Read, T. R. C. \& Cressie, N. A. C. in Goodness-of-fit Statistics for Discrete Multivariate Data 136-139 (Springer, New York, 1988).

19. Shuster, S. M. \& Wade, M. J. Female copying and sexual selection in a marine isopod crustacean. Anim. Behav. 42, 1071-1078 (1991).

20. Shuster, S. M. in Crustacean Sexual Biology (eds Bauer, R. T. \& Martin, J. W.) 91-110 (Columbia Univ. Press, New York, 1991).

21. Levins, R. Evolution in Changing Environments (Princeton Univ. Press, Princeton, 1968).

22. Slatkin, M. On the equilibration of fitnesses by natural selection. Am. Nat. 112, 845-859 (1978).

23. Maynard Smith, J. Evolution and the Theory of Games (Cambridge Univ. Press, New York, 1982).

24. Lively, C. M. Canalization versus developmental conversion in a spatially variable environment. Am Nat. 128, 561-572 (1986).

25. Slatkin, M. The evolutionary response to frequency and density dependent interactions. Am. Nat. 114, 384-398 (1979)

26. Wright, S. Evolution and Genetics of Populations Vol. 2 (Univ. of Chicago Press 1969).

27. Wade, M. J., Shuster, S. M. \& Stevens, L. Bottlenecks, founder events and inbreeding: Experimental studies of the response to selection with Tribolium. Evolution 50, 723-733 (1996).

28. Shuster, S. M. Changes in female anatomy associated with the reproductive molt in Paracerceis sculpta (Holmes), a semelparous isopod crustacean. J. Zool. 225, 365-379 (1991).

29. Shuster, S. M. Courtship and female mate selection in a semelparous isopod crustacean (Paracerceis sculpta). Anim. Behav. 40, 390-399 (1990).

30. Tinturier-Hamelin, E. Sur le polychromatisme de l'isopode Flabellifere Dynamene bidentata (Adams) II. Etude genetique du mutant bimaculata partiellement. Cah. Biol. Mar. 4, 473-591 (1967).

Acknowledgements. This research was supported by the NSF and by organized research and departmental funding from Northern Arizona University, and was authorized by the Mexican Government. We thank M. Wade and B. Charlesworth for reviewing data and earlier drafts of the manuscript; Y. Toquenag for statistical advice and for a program for calculating exact $\chi^{2}$ tests; D. Dorado, S. Juarez, S. Hag, H. Baitoo, S. Bhakta, Y. Bhakta, S. Brekhus; H. Yoon; N. Kim, M. Kim, U. Rao and L. Lynch for assistance in maintaining laboratory animals; and V. Jormalainen, P. Nelson, K. Johnson, G. Davis and M. Pitts for discussion.

Correspondence and requests for materials should be addressed to S.M.S. (e-mail stephen.shuste @nau.edu).

\section{Different types of fear- conditioned behaviour mediated by separate nuclei within amygdala}

\section{Simon Killcross ${ }^{\star}$, Trevor W. Robbins \& Barry J. Everitt}

Department of Experimental Psychology, University of Cambridge,

Downing Street, Cambridge CB2 3EB, UK

The amygdala has long been thought to be involved in emotional behaviour ${ }^{1,2}$, and its role in anxiety and conditioned fear has been highlighted $^{3,4}$. Individual amygdaloid nuclei have been shown to project to various cortical and subcortical regions implicated in affective processing ${ }^{5-7}$. Here we show that some of these nuclei have separate roles in distinct mechanisms underlying conditioned fear responses. Rats with lesions of the central nucleus exhibited reduction in the suppression of behaviour elicited by a conditioned fear stimulus, but were simultaneously able to direct their actions to avoid further presentations of this aversive stimulus. In contrast, animals with lesions of the basolateral amygdala were unable to avoid the conditioned aversive stimulus by their choice behaviour, but exhibited normal conditioned suppression to this stimulus. This double dissociation demonstrates that distinct neural systems involving separate amygdaloid nuclei mediate different types of conditioned fear behaviour. We suggest that theories of amygdala function should take into account the roles of discrete amygdala subsystems in controlling different components of integrated emotional responses.

Investigations of the neural basis of pavlovian fear conditioning and its role in anxiety have suggested that the lateral nucleus of the amygdala is the site of convergence of neural pathways that carry information about conditioned stimuli (CSs) and aversive reinforcers (USs) ${ }^{4,6}$. The emotional expression of this learned association may then be mediated by neural connections from the lateral to the central nucleus of the amygdala ${ }^{4}$, which, through its projections to hypothalamic and brainstem areas, is thereby able to coordinate the behavioural, endocrine and autonomic responses that form an integrated emotional response ${ }^{8}$.

Serial processing in these regions of the amygdala is known to be involved in the acquisition and expression of conditioned fear responses to aversive CSs, such as freezing and fear-potentiated startle in animals ${ }^{3-6}$. However, the role of these regions in alternative indices of fear conditioning, including the instrumental choice responses involved in avoidance or conflict behaviour, is much less clear'. We therefore wished to investigate whether all forms of fear conditioning are mediated by this serial information flow between the lateral and basal nuclei to the central nucleus of the amygdala. To achieve this we designed a fear-conditioning procedure in rats in which the development of an aversive CS-US association could be assessed simultaneously by examination of two dissociable fear responses in the same animal. The aversive CSUS association created by this procedure would not only produce a pavlovian conditioned fear response, but would also provide the necessary information for animals to solve an operant discrimination that would lead to the avoidance of future presentations of the aversive stimulus.

Rats were trained on a concurrent conditioned-suppression and conditioned-punishment task (see Methods). Pressing one lever in an operant chamber produced an aversive conditioned stimulus $(\mathrm{CS}+)$, pressing the other lever produced control presentations of a

* Present address: Department of Psychology, University of York, Heslington, York YO1 5DD, UK. 